\title{
Expanding the Family of Tetrahalide Iron Complexes: Synthesis, Structure and Biological Applications.
}

Nusrat Abedin, ${ }^{[a]}{ }^{\ddagger}$ Abdullah Hamed A Alshehri, ${ }^{\text {[a] }}$ Ali M A Almughrbi, [a] Olivia Moore, ${ }^{[a]}$ Sheikh Alyza, ${ }^{[a]}$ Elizabeth K. Rusbridge, ${ }^{[b]}$ Naqash Masood, ${ }^{[c]}$ Biola F. Egbowon, ${ }^{[a]}$ Alan J. Hargreaves, ${ }^{\text {[a] }}$ Felix DafhnisCalas, ${ }^{*}[\mathrm{~d}]$ and Anthony J. Fitzpatrick ${ }^{*}[\mathrm{~b}]$

[a] Department of Biosciences, Nottingham Trent University, Nottingham, NG11 8NS, UK

[b] Department of Chemistry and Forensics, Nottingham Trent University, Nottingham, NG11 8NS, UK

Email: anthony.fitzpatrick@ntu.ac.uk

[c] School of Life Sciences, Keele University, Keele, Staffordshire, ST5 5BG, UK

[d] School of Life Sciences, Queens Medical Centre, University of Nottingham, NG7 2UH, UK

Email: felix.Dafhnis-calas@nottingham.ac.uk

\#Current Address: Institute of Food Science and Technology (IFST), Bangladesh Council of Scientific and Industrial Research (B CSIR), Dr Qudrat-I-Khuda Road, Dhanmondi, Dhaka 1205, Bangladesh.

Abstract: A neutral octahedral mononuclear iron(II) tetrabromide complex, [ $\left.\mathrm{Fe}(\mathrm{Hampy})_{2} \mathrm{Br}_{4}\right]$, that consists of equatorial bromide and protonated aminopyrazinium axial ligands is successfully synthesised through redox chemistry and analysed using X-ray crystallography. The iron(II) oxidation state is balanced by the protonated pyrazinium nitrogen just outside the coordination sphere. The biological properties of this and two other related complexes are investigated using both Gramnegative and Gram-positive bacteria as well as methicillin resistant strains. They all exhibit some antimicrobial properties albeit at moderate to poor concentrations. However, the tetrahalide complexes analysed exhibit excellent anti biofilm properties well below cytotoxic levels.

Keywords: Coordination Chemistry, Halides, Iron, Crystallography, Biofilms 


\section{Introduction}

Tetrachloroferrates and tetrabromoferrates have been utilised in many areas of materials chemistry for their easy synthesis and magnetic properties.[1-4] They have been widely used in areas such as functional ionic liquid synthesis,[5-7] and catalysis.[8,9] Most examples are trivalent and are balanced by either group 1 or 2 metals or simple positively charged nitrogen species, e.g. ammonium, pyridinium, imidazolium.[10-13]

In our previous work, we synthesised an octahedral Fe(II) complex that consisted of four equatorial chloride ligands with two axial aminopyrazinium ligands, $\left[\mathrm{Fe}\left(\mathrm{II}_{)} \mathrm{Cl} 4(\mathrm{HAmpy})_{2}\right]\right.$, complex 1.[14] Searching the Cambridge Structural Database (CSD)[15] reveals that the complex, $\mathrm{Fe}(\mathrm{II}) \mathrm{Cl}_{4}(\mathrm{HAmpy})_{2}$, is the only example of a mononuclear octahedral tetrahalide iron derivative where the balancing charges are on the same molecule rather than an exogenous spectator cation. There are numerous examples of iron species with several chloride ligands; however, they are predominantly polymeric in nature and/or have exogenous cations to balance charge.

In this work, we wanted to expand the tetrahalide motif to bromide ligands. A search of the CSD reveals there are only six examples of an octahedral Fe complex with four bromide ligands with a published structure. Of these six structures, three are discrete multinuclear clusters. The first, an undecanuclear mixed metal cluster containing iron, gallium and potassium bridged by bromides, by Linti et al.[16] Here the central iron is coordinated to four bromides with the axial positions being occupied by bridging oxides. The second is a trinuclear iron cluster with bridging bromide ligands with $\beta$-diketiminate terminal ligands by Jones et al.[17] The third example is a mixed trinuclear cluster with a central iron ion coordinated to four bridging bromides that coordinate a zinc ion capped by THF and p-tolyl groups by Bedford et al.[18] In these examples all the bromide ligands coordinated to iron are bridging and therefore do not constitute a formally tetra anionic metal centre as seen in $\mathrm{Fe}(\mathrm{II}) \mathrm{Cl}_{4}(\mathrm{HAmpy}) 2$. The other three examples are polymeric 
in nature; the first example from Reiff et al. is a catena-bridged ferrous bromide derivative with water molecules in the axial positions.[19] Work by Schmidt et al. utilising cyanopyridine forms polymeric chains of iron bromide units where there are two possible motifs, $[20,21]$ one where the bridging equatorial bromides are the linkers and the other where there is both the bridging bromides as well as coordination at the cyanide nitrogen. All three polymeric examples contain the iron centre with equatorial bromides with a differing axial ligand. However, none of these examples possess the tetra anionic ligand set found in our previous work.

This work presents the synthesis of $\left[\mathrm{Fe}(\mathrm{Hampy})_{2} \mathrm{Br} 4\right]$, complex 2 , using the same redox-based synthesis found in our previous work, wherein the oxidation of salicylaldehyde is facilitated by the reduction of ferric bromide to a ferrous salt resulting in the isolation of 2 , figure 1 . We also present the ferric complex, $\left[\mathrm{Fe}(\right.$ bipy $\left.)(\mathrm{Sal}) \mathrm{Cl}_{2}\right] \cdot \mathrm{CH}_{3} \mathrm{CN}$, complex 3, that results from the addition of 2,2 '-bipyridine to the synthesis of $\mathbf{1}$. This seemingly stops the redox process and stabilises the ferric chloride. We present the potential for antimicrobial effects along with the key structural features of the novel complexes.
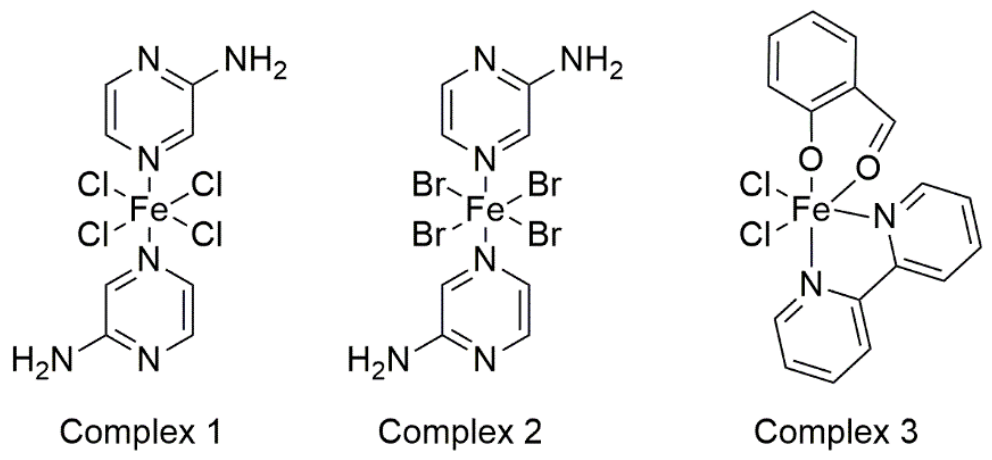

Complex 3

Figure 1: Structure of the iron halide complexes 1, 2, and 3. 


\section{Results and Discussion}

\section{Structural analysis of complexes 2 and 3}

Complex 2 results from the modified synthesis previously reported for complex $\mathbf{1}$. The structural

motif is identical to that of complex 1. 2 also sits on a crystallographic centre of symmetry resulting only 3 unique metal-ligand bond lengths. The use of ferric bromide rather than chloride results in an iron (II) species with equatorial bromide ligands balanced by aminopyrazinium ligands in the axial positions (Figure 2A). As discussed previously, the complex is the result of a redox couple between the $\mathrm{Fe}$ (III) species and the aldehyde used in the synthesis. It is a formally tetra anionic equatorial ligand set balanced by the pyrazinium nitrogen just outside the immediate coordination sphere.

Complex 3 results from the competitive addition of a co-ligand to the mixture containing the ferric chloride iron source. The addition of the bipyridine ligand inhibits the redox chemistry and forms a more straightforward Fe (III) complex containing one bidentate coordinated bipyridine, two chloride ligands and finally, one salicylaldehyde coordinated through the aldehyde lone pair and a deprotonated phenolate oxygen, as shown in Figure $2 \mathrm{~B}$.

The metal-ligand bond lengths in each complex indicate a high spin ion $S=2$ for $2, S=5 / 2$ for 3, Table 1.[22-24] 
A

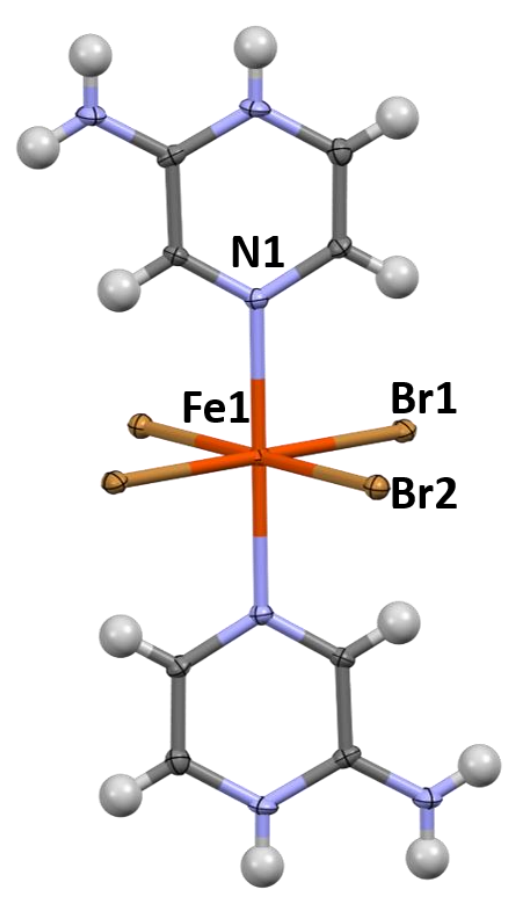

B

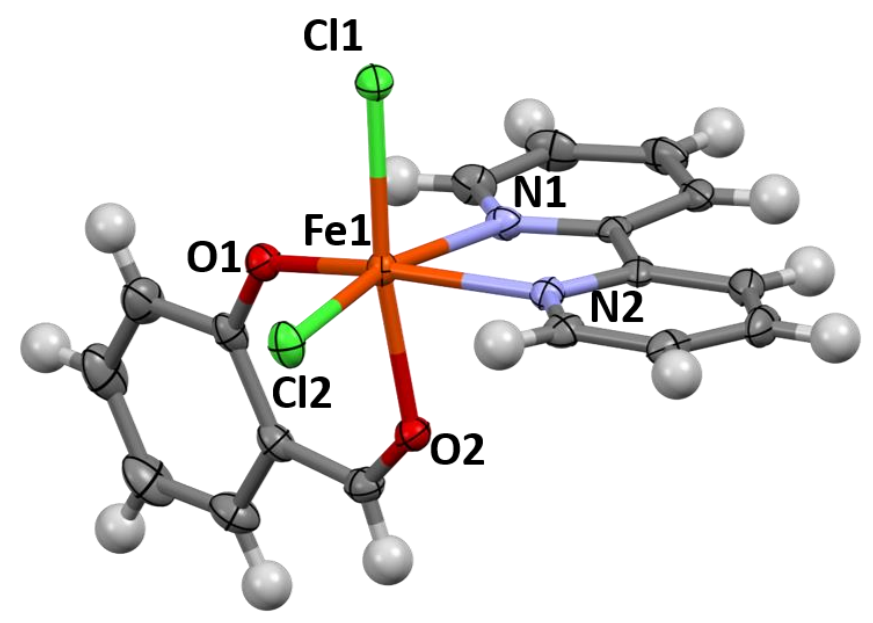

Figure 2: A) Structure of complex 2 at $150 \mathrm{~K}$; B) Structure of complex 3 at $150 \mathrm{~K}$, solvent removed for clarity.

. Table 1: Bond lengths for complexes 2 and 3 at $150 \mathrm{~K}$.

\begin{tabular}{|c|c|c|c|}
\hline Complex 2 & $\AA ̊$ & Complex 3 & $\AA ̊$ \\
\hline Fe-N1 & $2.233(3)$ & $\mathrm{Fe}-\mathrm{N} 1$ & $2.170(3)$ \\
\hline $\mathrm{Fe}-\mathrm{Br} 1$ & $2.6267(9)$ & Fe-N2 & $2.191(3)$ \\
\hline \multirow[t]{4}{*}{ Fe-Br2 } & $2.6192(9)$ & $\mathrm{Fe}-\mathrm{O} 1$ & $1.917(2)$ \\
\hline & & $\mathrm{Fe}-\mathrm{O} 2$ & $2.101(2)$ \\
\hline & & $\mathrm{Fe}-\mathrm{Cl} 1$ & $2.3117(9)$ \\
\hline & & $\mathrm{Fe}-\mathrm{Cl} 2$ & $2.2894(9)$ \\
\hline
\end{tabular}

Complex 2 is isostructural to the previously published complex 1.[14] The same hydrogenhalogen bonding 3-D architecture is present throughout the lattice with the hydrogen on the 
pyrazine nitrogen and the amine interacting with the bromide ligands of neighbouring complexes. Here longer contacts are observed between the donor and acceptor due to the larger atomic radius of bromine versus chlorine. There are two major motifs of non-covalent interactions in 2. One, where a 2-D sheet is formed, Figure 3, this occurs between the hydrogens on both the amine and protonated pyrazinium moieties, and the bromide ligands of two neighbouring complexes. The length of these interactions, $\mathrm{Br}-\mathrm{H}(\mathrm{N}) 2.78-2.91 \AA$, falls within accepted lengths.[25] The second motif is the non-covalent "stitching" together of these 2-D sheets. There is a shorter $\mathrm{Br}-\mathrm{H}(\mathrm{N})$ interaction, $2.46 \AA$, between each sheet.

Complex $\mathbf{3}$ exhibits only small $\pi-\pi$ overlap between the bipyridine ligands over neighbouring complexes forming pseudo-dimers, Figure 4. The C-C intermolecular contact distances are ca. $3.4 \AA$ and the rings are coplanar.

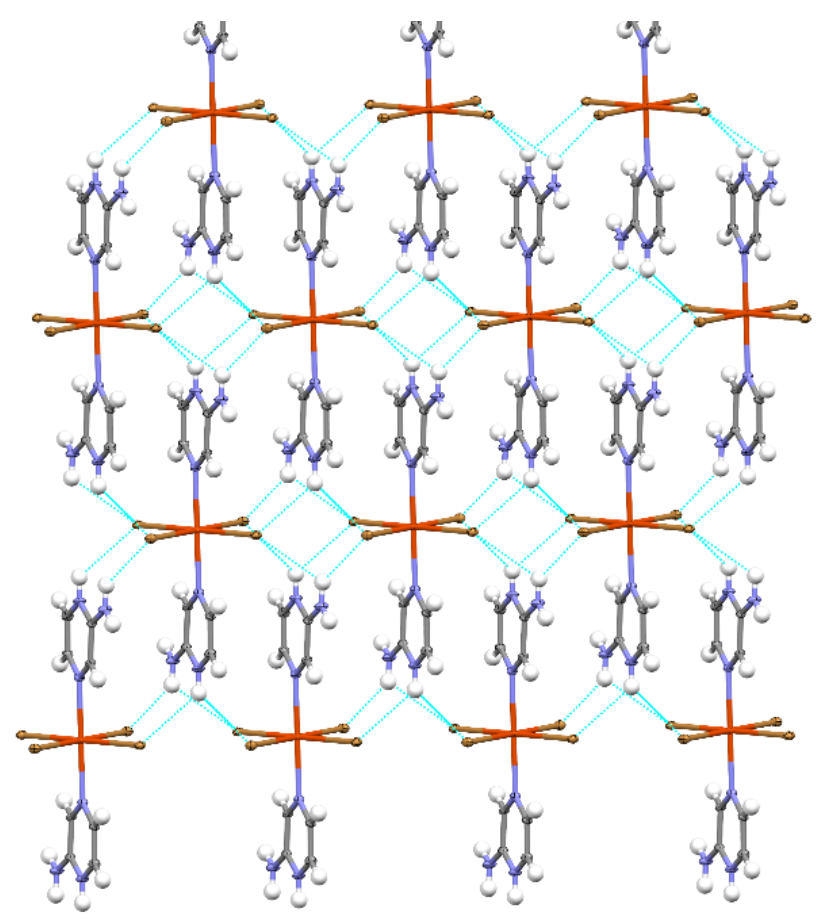


Figure 3: Hydrogen-halogen interactions between neighbouring complexes in complex 2. Hydrogen bonding in blue.

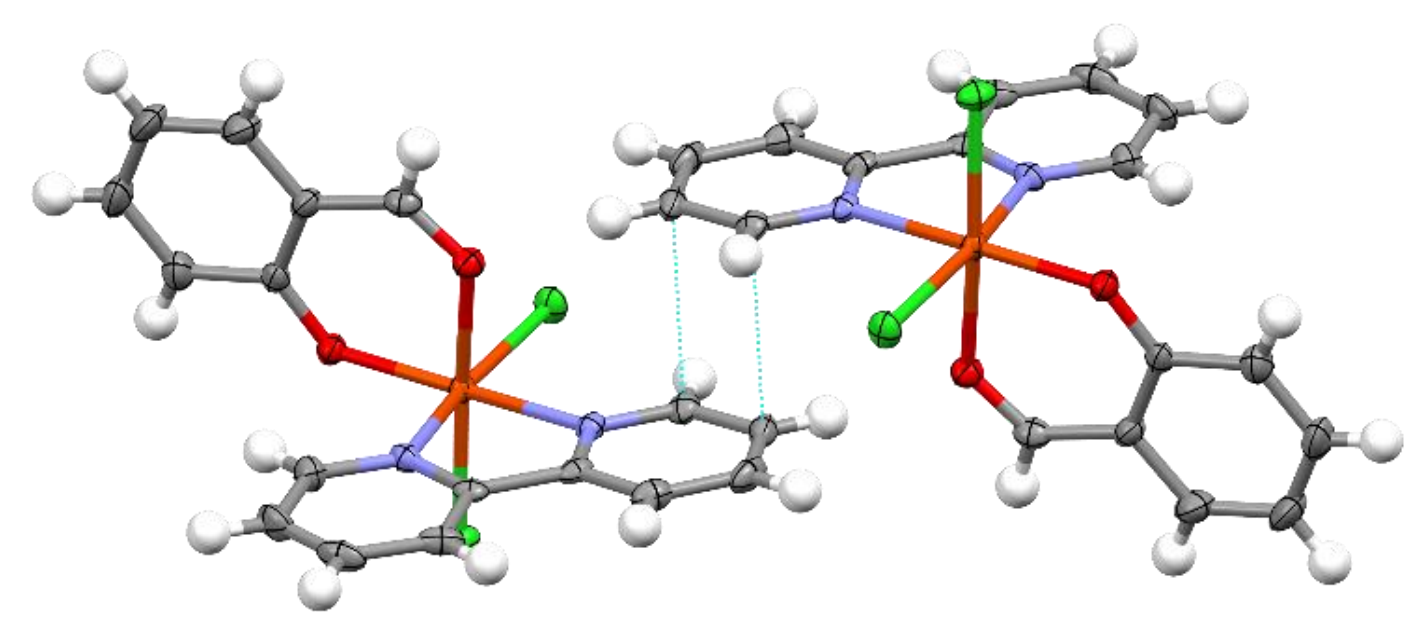

Figure 4: $\pi-\pi$ dimers in complex 3. Hydrogen bonding in blue.

\section{Biological Properties Analysis}

Multidrug resistance is becoming a major worldwide problem. As such, many metal complexes are being looked at as potential antimicrobials.[26] The study by Frei et al. exhibits that a very low number of iron complexes meet the criteria of being active and non-toxic. We have therefore investigated the antimicrobial and cytotoxicity of complexes 1-3. The bacterial strains used in these studies were the methicillin-resistant Staphylococcus aureus NCTC 12493, Pseudomonas aeruginosa strain PAO1 and Escherichia coli NCTC 10418. (For full details on methods used please see the supporting information.)

Well-diffusion tests, using complexes 1-3, were performed to investigate any possible inhibitory effect on bacterial cell growth. The results of this experiment indicated that the three iron halide complexes and their $\mathrm{FeCl}_{3}$ and $\mathrm{FeBr}_{3}$ precursor metal salts inhibited bacterial cell growth, while 2-aminopyrazine did not, Figure S1. The complex zone of inhibition ranged from 
15 to $25 \mathrm{~mm}$. However, high concentrations were needed to observe inhibition of bacterial growth. Therefore, agar dilution tests using complexes 1-3 were performed to determine the lowest concentration at which complexes prevented bacterial cell growth. The experimental findings showed that the minimal inhibitory concentration (MIC) of complexes 1 and 2 were 5 $\mathrm{mM}$ and $3.5 \mathrm{mM}$, respectively. However, the MIC value of complex 3 was $10 \mathrm{mM}$ for MRSA and $P$. aeruginosa, whereas in the E. coli experiment it was 4-fold higher, at $40 \mathrm{mM}$, Table 2 . A time-kill experiment was next performed to evaluate the anti-microbial activity of the iron halides over time, Figure S2. The result of the study indicated a bactericidal mode of action of the novel-iron complexes as they caused a three times log reduction of the CFU/mL.[27] This bactericidal mode of action was also suggested by the increase amount of extracellular DNA associated to bacterial strains exposed to the iron-halide complexes, Figure S2.D.

Table 2. Minimal inhibitory concentration of the iron halide complexes and their ligands.

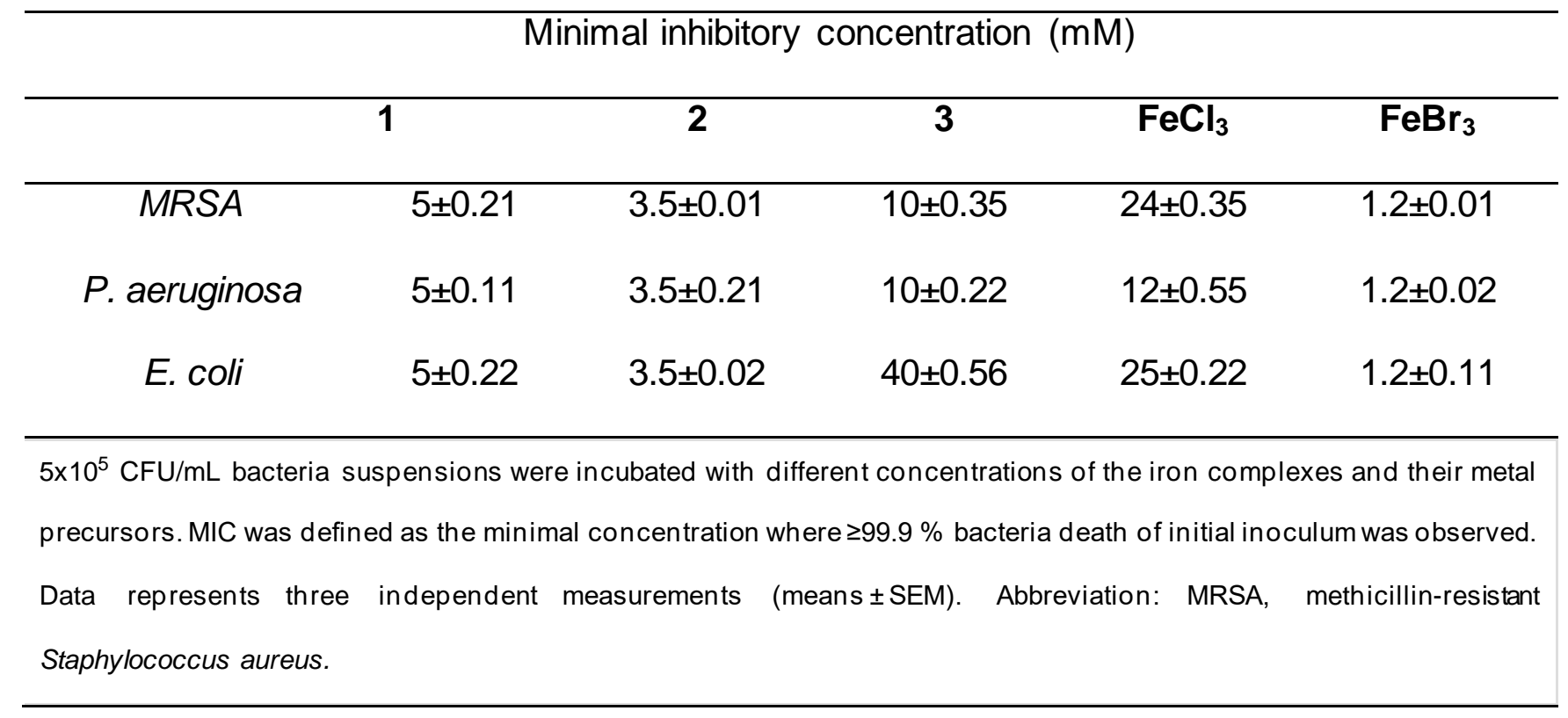

The cytotoxic properties were investigated by Alamar Blue assays and MTT assays, Figure S3. The MTT reduction assay was first used to study the in vitro effects of the iron complexes 
on the viability of the HaCaT cell line. The main results from the MTT assay were that $\mathbf{1}$ and $\mathbf{2}$ exhibited non-cytotoxic behaviour at concentrations of $1 \mathrm{mM}$ and below, with 3 at concentrations of $0.2 \mathrm{mM}$ and below. This could be ascribed to the difference in oxidation state and/or ligand environment. The Alamar Blue assays agreed with the MTT results. However, $\mathbf{1}$ and $\mathbf{2}$ exhibited some slight decrease in cell viability at $1 \mathrm{mM}$ concentrations.

The last investigation that was performed was the effect of complexes 1-3 on the formation and reduction of MRSA biofilms. Biofilms, which are self-produced matrices of extracellular polymeric substances that aid in strengthening microorganisms to external stresses including antimicrobial agents, are an important mechanism for MRSA to adhere to both living and nonliving materials.[28,29] Only in the last couple of decades has the predominant life-mode of most bacterial species been realized to be biofilm growth. Therefore, interference with this mechanism can aid in synergistic treatment of resistant strains in high risk settings. Here we investigated the effect of 1-3 on both the formation of biofilms from MRSA and the reduction of formed biofilms, Figure 5. An inhibition of biofilm formation can be observed with complex 1 and 2 at concentrations lower than $1 \mathrm{mM}$. This trend continues when reduction of premade biofilms is investigated, with complex 1 and 2 being able to reduce the biofilm present at concentrations less than $1 \mathrm{mM}$. Complex 3 requires far higher concentrations to exhibit a relatively weak change in both inhibition and reduction of biofilms. These values are of interest for $\mathbf{1}$ and $\mathbf{2}$ as they are below cytotoxic levels as observed in the MTT and Alamar Blue assays. Iron salts are not unknown to affect the biofilm production in bacteria with several examples using basic iron salts exhibiting a reduction in biofilm production. The concentrations of iron sources range from low $\mu \mathrm{M}$ to $\mathrm{mM}$.[30-32] However, there is no route to further derivatisation or functionalisation with these simple iron salts and not all examples exhibit an effect against resistant strains. Several examples of the use of iron oxide nanoparticles as an effective anti-biofilm agent have been published but the route for derivation is to change the 
periphery so it acts more as a delivery system rather than a chemical agent.[33-35] Research has been conducted into the role of iron and other metal in the production of biofilms, and it has been determined that iron plays a very important role with iron scavengers inhibiting biofilm formation also.[36-38]

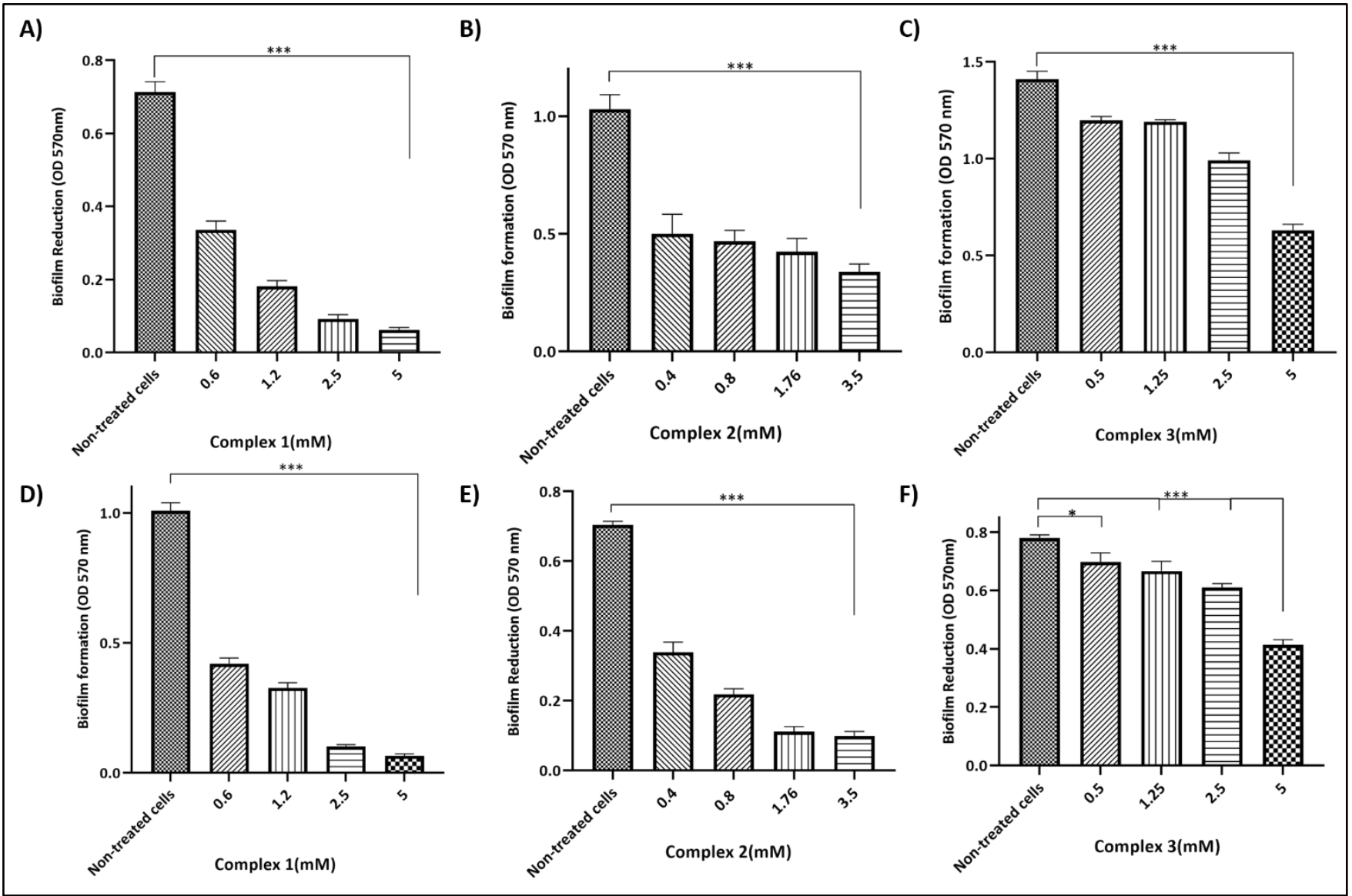

Figure 5: Anti-biofilm activity of the iron halide complexes. A), B) and C): Prevention of bacteria biofilm - the MRSA strains grown in a 96-wells plate were co-incubated with different concentrations of the iron complexes at $37^{\circ} \mathrm{C}$ for 24 hours. Crystal violet staining of the cells attached to the bottom of the plate was followed by solubilisation of the dye and optical density measurement at $570 \mathrm{~nm}$. D), E) and F): Biofilm dispersal - preformed biofilms of the MRSA strain were incubated at $37^{\circ} \mathrm{C}$ for 24 hours with RPMl med ia containing different concentrations of the iron halide compounds $(\leq \mathrm{MIC})$. Removal of the medium was then followed by crystal violet staining, dye solubilisation and optical density measurement at 570nm. Data were analysed statistically by oneway ANOVA. The graph represents the average absorbance of the crystal violet-stained biofilms formed on microtiter well plates. ${ }^{* *} \mathrm{P}<0.001$ versus control. 
The inhibition of biofilm formation and the disintegration of preformed biofilms point toward a possible multimodal action of the complexes. The initial inhibition of formation can come from inhibition of bacterial surface adhesion or interfering with the quorum sensing system of the bacteria.[39,40] Complexes 1 and 2 may aid in this due to supramolecular interactions with the media or the bacteria cells themselves. Other modes of inhibition and degradation come from alterations to the genetic expression of the bacteria and changes in enzymatic processes, most notably, the bacterial second messenger bis- $\left(3^{\prime}-5^{\prime}\right)$-cyclic diguanosine monophosphate (c-di-GMP) involving diguanylate cyclases and specific phosphodiesterases.[41] The mode of action and mechanisms in biofilm inhibition caused by compounds 1 and 2 are complex areas to understand and will be a main aim for further studies.

\section{Conclusion}

In conclusion, we have added to the octahedral tetrabromide family of complexes. To the best of our knowledge we have synthesised the second example of a tetra anionic ligand set around a ferrous ion that is balanced by internal positive charges on the molecule rather than an exogenous cation. The effect of addition of co-ligands was observed in complex 3 where the co-ligand inhibited the redox synthesis observed in 1 and 2 . The change in oxidation and coordination environment has a large impact on the supramolecular properties of the complex. The intricate 3-D architecture found in the tetrahalide systems is lost and replaced with a weak $\pi-\pi$ interaction. This is an area for exploration to expand the set of complexes available further by changing the redox couple and/or possible co-ligand. We have also investigated the biological 
properties of the complexes from our previous work and the novel complexes in this work. While the concentrations needed to observe antimicrobial properties are relatively high compared to commercially available antimicrobials, the anti-biofilm properties show promise as they are below the cytotoxic levels and in the 400-600 $\mu \mathrm{M}$ range for $\mathbf{1}$ and $\mathbf{2}$. This result gives rise to potential for a scaffold, with which further derivation could yield promising results for synergistic external control of bacterial infection.

\section{Experimental Section}

\section{Synthesis of the Fe halide complexes}

Synthesis of Complex 1, [ Fe(Hampy) $\left.{ }_{2} \mathrm{Cl} / 4\right]$, was performed according to our previous work.[14]

Synthesis of Complex 2, [ $\left.\mathrm{Fe}(\mathrm{Hampy})_{2} \mathrm{Br} 4\right]$, was adapted from complex 1: 2aminopyrazine $(0.095 \mathrm{~g}, 1.00 \mathrm{mmol})$ was added to salicylaldehyde $(0.105 \mathrm{~mL}, 1.00$ $\mathrm{mmol}$ ) in 1:1 methanol/acetonitrile $(15 \mathrm{~mL})$. Ferric bromide $(0.400 \mathrm{~g}, 1.35 \mathrm{mmol})$ was added to the solution, initially resulting in a red colour, which later became dark purple. This mixture was then filtered after a further 10 min of stirring. Upon evaporation of the solvent, dark purple crystals were isolated and washed in acetone. Yield: $0.1839 \mathrm{~g}$, $32 \%$. IR: Umax (neat) $/ \mathrm{cm}^{-1} 3306,3088,1649,1620,770,706$. Elemental, Theory (Found): C 16.19(16.23), H 1.78(1.84), N 14.86(14.88).

Synthesis of Complex 3, [Fe(bipy)(Sal) $\left.\mathrm{Cl}_{2}\right] \cdot \mathrm{CH}_{3} \mathrm{CN}$ : 2-aminopyrazine $(0.095 \mathrm{~g}, 1.00$ $\mathrm{mmol}$ ) was added to salicylaldehyde $(0.122 \mathrm{~g}, 1.00 \mathrm{mmol})$ in $1: 1$ methanol/acetonitrile $(15 \mathrm{~mL})$ and stirred for $10 \mathrm{~min}$. Ferric chloride hydrate $(0.541 \mathrm{~g}, 2.00 \mathrm{mmol})$ was then added to this solution, resulting in a dark red colour, immediately followed by the 
addition of 2,2'-bipyridyl $(0.156 \mathrm{~g}, 1.00 \mathrm{mmol})$. The solution was filtered after $20 \mathrm{~min}$ stirring and small, dark red plate-like crystals formed after several days of slow solvent evaporation. Yield: 0.2589 g. IR: Umax (neat) / $\mathrm{cm}^{-1} 3304,3051,1655,1620,773,678$. Elemental, Theory (Found): C 51.27(50.95), H 3.62(3.39), N 9.44(7.55). The elemental analysis for complex $\mathbf{3}$ shows there is loss of solvation between isolation and analysis. The values for the non-solvated complex are C, 50.53; H, 3.24; N 6.93. The elemental analysis found for complex 3 exhibits approximately $0.35 \mathrm{CH}_{3} \mathrm{CN}$ in the sample.

\section{Notes}

Crystallographic Data for complex 2 and $\mathbf{3}$ can be found at the CCDC data base 1983590 and 1953591, respectively.

\section{Acknowledgements}

The authors gratefully acknowledge Bangabandhu Science and Technology Fellowship Trust, Bangladesh, and Bangladesh Council of Scientific and Industrial Research (BCSIR), Bangladesh, for awarding fellowship to NA and supporting the study. AJH, AJF and FDC also acknowledge School of Science and Technology, Nottingham Trent University, UK, for financial support and necessary research facilities.

[1] T.B. Swanson, V.W. Laurie, Electron magnetic resonance and electronic spectra of tetrachloroferrate(III) ion in nonaqueous solution, J. Phys. Chem. 69 (1965) 244-250. https://doi.org/10.1021/j100885a036.

[2] Y. Masuda, M. Kuratsu, S. Suzuki, M. Kozaki, D. Shiomi, K. Sato, T. Takui, K. Okada, Preparation and magnetic properties of verdazyl-substituted 
dihydrophenazine radical cation tetrachloroferrate salts, Polyhedron. 28 (2009) 1950-1954. https://doi.org/10.1016/j.poly.2008.11.002.

[3] R. Shaviv, R.L. Carlin, Magnetochemistry of the tetrahaloferrate(III) ions. 4. Heat capacity and magnetic ordering in bis[4-chloropyridinium tetrachloroferrate(III)]-4-chloropyridinium chloride, Inorg. Chem. 31 (1992) 710-712. https://doi.org/10.1021/ic00030a034.

[4] B.D. James, J. Mrozinski, J. Klak, B.W. Skelton, A.H. White, Tetrachloroferrate(III) Complexes Containing Some Heteroaromatic Organic Cations: Structures and Magnetic Properties, Zeitschrift Für Anorg. Und Allg. Chemie. 635 (2009) 317-322. https://doi.org/10.1002/zaac.200800429.

[5] D. Kogelnig, A. Stojanovic, F. V.d. Kammer, P. Terzieff, M. Galanski, F. Jirsa, R. Krachler, T. Hofmann, B.K. Keppler, Tetrachloroferrate containing ionic liquids: Magnetic- and aggregation behavior, Inorg. Chem. Commun. 13 (2010) 1485-1488. https://doi.org/10.1016/j.inoche.2010.08.023.

[6] E. Santos, J. Albo, A. Irabien, Magnetic ionic liquids: Synthesis, properties and applications, RSC Adv. 4 (2014) 40008-40018. https://doi.org/10.1039/c4ra05156d.

[7] A. García-Saiz, P. Migowski, O. Vallcorba, J. Junquera, J.A. Blanco, J.A. González, M.T. Fernández-Díaz, J. Rius, J. Dupont, J. Rodríguez Fernández, I. de Pedro, A Magnetic lonic Liquid Based on Tetrachloroferrate Exhibits Three-Dimensional Magnetic Ordering: A Combined Experimental and Theoretical Study of the Magnetic Interaction Mechanism, Chem. Eur. J. 20 (2014) 72-76. https://doi.org/10.1002/chem.201303602.

[8] K.R. Barnard, V.R. Bright, R.J. Enright, K.M. Fahy, A.C. Liu, P.E. Hoggard, 
Heterogeneous Catalysis by Tetraethylammonium Tetrachloroferrate of the Photooxidation of Toluene by Visible and Near-UV Light, Catalysts. 8 (2018) 79. https://doi.org/10.3390/catal8020079.

[9] A. Khazaei, A.R. Moosavi-Zare, S. Firoozmand, M.R. Khodadadian, Synthesis, characterization and application of 3-methyl-1-sulfonic acid imidazolium tetrachloroferrate as nanostructured catalyst for the tandem reaction of $\beta$ naphthol with aromatic aldehydes and amide derivatives, Appl. Organomet. Chem. 32 (2018). https://doi.org/10.1002/aoc.4058.

[10] B. Zaslow, The structure of the tetrachloroferrate (III) ion, lowa State University, Digital Repository, 1956. https://doi.org/10.31274/rtd-18081316095.

[11] R.R. Richards, N.W. Gregory, The crystal structure of sodium tetrachloroferrate(III), J. Phys. Chem. 69 (1965) 239-244. https://doi.org/10.1021/j100885a035.

[12] J.W. Lauher, J.A. Ibers, Structure of Tetramethylammonium Tetrachloroferrate(II), [N(CH3)4]2[FeCl4]. Comparison of Iron(II) and Iron(III) Bond Lengths in High-Spin Tetrahedral Environments, Inorg. Chem. 14 (1975) 348-352. https://doi.org/10.1021/ic50144a029.

[13] D. Wyrzykowski, R. Kruszyński, J. Kłak, J. Mroziński, Z. Warnke, Synthesis and magnetic characteristics of new tetrachloroferrates(III) with 2methylpyridinium, 3-methylpyridinium and 4-methylpyridinium cations: X-ray crystal structure of 4-methylpyridinium tetrachloroferrate(III), Inorganica Chim. Acta. 360 (2007) 3354-3360. https://doi.org/10.1016/j.ica.2007.04.001.

[14] E.K. Rusbridge, Y. Peng, A.K. Powell, D. Robinson, A.J. Fitzpatrick, An 
octahedral tetrachlorido Fe(ii) complex with aminopyrazinium ligands from a serendipitous redox synthesis exhibiting magnetic exchange through noncovalent 3-D architectures, Dalton Trans. 47 (2018) 7644-7648. https://doi.org/10.1039/c8dt01401a.

[15] C.R. Groom, I.J. Bruno, M.P. Lightfoot, S.C. Ward, The Cambridge structural database, Acta Crystallogr. Sect. B Struct. Sci. Cryst. Eng. Mater. 72 (2016) 171-179. https://doi.org/10.1107/S2052520616003954.

[16] G. Linti, G. Li, H. Pritzkow, On the chemistry of gallium: Part 19. Synthesis and crystal structure analysis of novel complexes containing $\mathrm{Ga}-\mathrm{FeCp}(\mathrm{CO}) 2-$ fragments, J. Organomet. Chem. 626 (2001) 82-91. https://doi.org/10.1016/S0022-328X(01)00656-8.

[17] R.P. Rose, C. Jones, C. Schulten, S. Aldridge, A. Stasch, Synthesis and Characterization of Amidinate-Iron(I) Complexes: Analogies with $\beta$ Diketiminate Chemistry, Chem. Eur. J. 14 (2008) 8477-8480. https://doi.org/10.1002/chem.200801071 .

[18] A.M. Messinis, S.L.J. Luckham, P.P. Wells, D. Gianolio, E.K. Gibson, H.M. O’Brien, H.A. Sparkes, S.A. Davis, J. Callison, D. Elorriaga, O. HernandezFajardo, R.B. Bedford, The highly surprising behaviour of diphosphine ligands in iron-catalysed Negishi cross-coupling, Nat. Catal. 2 (2019) 123-133. https://doi.org/10.1038/s41929-018-0197-z.

[19] R.E. Greeney, C.P. Landee, J.H. Zhang, W.M. Reiff, A Bromide Analogue of a One-Dimensional Ising Ferromagnet: Trimethylammonium catena-Bis $(\mu-$ bromo)diaquoiron(II) Bromide, Inorg. Chem. 29 (1990) 3119-3125. https://doi.org/10.1021/ic00342a013. 
[20] M. Heine, L. Fink, M.U. Schmidt, 3-Cyanopyridine as a bridging and terminal ligand in coordination polymers, CrystEngComm. 20 (2018) 7556-7566. https://doi.org/10.1039/c8ce01568f.

[21] M. Heine, L. Fink, M.U. Schmidt, 4-Cyanopyridine complexes [MX2(4-CNpy): $\mathrm{X}$ ]n (with $\mathrm{X}=\mathrm{Cl}, \mathrm{Br}$ and $\mathrm{X}=1,2$ ): Crystal structures, thermal properties and a comparison with [MX2(3-CNpy)x]n complexes, CrystEngComm. 22 (2020) 2067-2082. https://doi.org/10.1039/c9ce02012h.

[22] P. Gütlich, Y. Garcia, H.A. Goodwin, Spin crossover phenomena in $\mathrm{Fe}(\mathrm{II})$ complexes, Chem. Soc. Rev. 29 (2000) 419-427. https://doi.org/10.1039/b003504l.

[23] M. Nihei, T. Shiga, Y. Maeda, H. Oshio, Spin crossover iron(III) complexes, Coord. Chem. Rev. 251 (2007) 2606-2621. https://doi.org/10.1016/j.ccr.2007.08.007.

[24] M.A. Halcrow, Structure: Function relationships in molecular spin-crossover complexes, Chem. Soc. Rev. 40 (2011) 4119-4142. https://doi.org/10.1039/c1cs15046d.

[25] P. Metrangolo, G. Resnati, Halogen Bonding, 2008. https://doi.org/10.1007/978-3-540-74330-9.

[26] A. Frei, J. Zuegg, A.G. Elliott, M. Baker, S. Braese, C. Brown, F. Chen, C. G. Dowson, G. Dujardin, N. Jung, A.P. King, A.M. Mansour, M. Massi, J. Moat, H.A. Mohamed, A.K. Renfrew, P.J. Rutledge, P.J. Sadler, M.H. Todd, C.E. Willans, J.J. Wilson, M.A. Cooper, M.A.T. Blaskovich, Metal complexes as a promising source for new antibiotics, Chem. Sci. 11 (2020) 2627-2639. https://doi.org/10.1039/c9sc06460e. 
[27] M. Balouiri, M. Sadiki, S.K. Ibnsouda, Methods for in vitro evaluating antimicrobial activity: A review, J. Pharm. Anal. 6 (2016) 71-79. https://doi.org/10.1016/j.jpha.2015.11.005.

[28] L. Hall-Stoodley, J.W. Costerton, P. Stoodley, Bacterial biofilms: From the natural environment to infectious diseases, Nat. Rev. Microbiol. 2 (2004) 95108. https://doi.org/10.1038/nrmicro821.

[29] H.C. Flemming, S. Wuertz, Bacteria and archaea on Earth and their abundance in biofilms, Nat. Rev. Microbiol. 17 (2019) 247-260. https://doi.org/10.1038/s41579-019-0158-9.

[30] S.K. Boda, S. Pandit, A. Garai, D. Pal, B. Basu, Bacterial siderophore mimicking iron complexes as DNA targeting antimicrobials, RSC Adv. 6 (2016) 39245-39260. https://doi.org/10.1039/c6ra02603f.

[31] D.J. Musk, D.A. Banko, P.J. Hergenrother, Iron Salts Perturb Biofilm Formation and Disrupt Existing Biofilms of Pseudomonas aeruginosa, Chem. Biol. 12 (2005) 789-796. https://doi.org/10.1016/j.chembiol.2005.05.007.

[32] L. Yang, K.B. Barken, M.E. Skindersoe, A.B. Christensen, M. Givskov, T. Tolker-Nielsen, Effects of iron on DNA release and biofilm development by Pseudomonas aeruginosa, Microbiology. 153 (2007) 1318-1328. https://doi.org/10.1099/MIC.0.2006/004911-0.

[33] E.N. Taylor, K.M. Kummer, N.G. Durmus, K. Leuba, K.M. Tarquinio, T.J. Webster, Superparamagnetic Iron Oxide Nanoparticles (SPION) for the Treatment of Antibiotic-Resistant Biofilms, Small. 8 (2012) 3016-3027. https://doi.org/10.1002/smll.201200575. 
[34] N.G. Durmus, T.J. Webster, Eradicating Antibiotic-Resistant Biofilms with Silver-Conjugated Superparamagnetic Iron Oxide Nanoparticles, Adv. Healthc. Mater. 2 (2013) 165-171. https://doi.org/10.1002/adhm.201200215.

[35] J. Li, R. Nickel, J. Wu, F. Lin, J. Van Lierop, S. Liu, A new tool to attack biofilms: Driving magnetic iron-oxide nanoparticles to disrupt the matrix, Nanoscale. 11 (2019) 6905-6915. https://doi.org/10.1039/c8nr09802f.

[36] S.R. Choi, B.E. Britigan, P. Narayanasamy, Dual Inhibition of Klebsiella pneumoniae and Pseudomonas aeruginosa Iron Metabolism Using Gallium Porphyrin and Gallium Nitrate, ACS Infect. Dis. 5 (2019) 1559-1569. https://doi.org/10.1021/acsinfecdis.9b00100.

[37] M.H. Lin, J.C. Shu, H.Y. Huang, Y.C. Cheng, Involvement of iron in biofilm formation by staphylococcus aureus, PLoS One. 7 (2012). https://doi.org/10.1371/journal.pone.0034388.

[38] S. Chhibber, D. Nag, S. Bansal, Inhibiting biofilm formation by Klebsiella pneumoniae B5055 using an iron antagonizing molecule and a bacteriophage, BMC Microbiol. 13 (2013) 174. https://doi.org/10.1186/1471-2180-13-174.

[39] A. Ghosh, N. Jayaraman, D. Chatterji, Small-Molecule Inhibition of Bacterial Biofilm, ACS Omega. 5 (2020) 3108-3115. https://doi.org/10.1021/acsomega.9b03695.

[40] K. Qvortrup, L.D. Hultqvist, M. Nilsson, T.H. Jakobsen, C.U. Jansen, J. Uhd, J.B. Andersen, T.E. Nielsen, M. Givskov, T. Tolker-Nielsen, Small Molecule Anti-biofilm Agents Developed on the Basis of Mechanistic Understanding of Biofilm Formation, Front. Chem. 7 (2019) 742. https://doi.org/10.3389/fchem.2019.00742. 
[41] O. Sarenko, G. Klauck, F.M. Wilke, V. Pfiffer, A.M. Richter, S. Herbst, V. Kaever, R. Hengge, More than enzymes that make or break cyclic Di-GMPlocal signaling in the interactome of GGDEF/EAL domain proteins of Escherichia coli, MBio. 8 (2017). https://doi.org/10.1128/mBio.01639-17. 